SILVA, L. G. A. da. Novos parâmetros de gestão na escola pública: o perfil e os sentidos meritocárticos contidos no processo de reforma educacional na rede pública estadual de ensino de Goiás

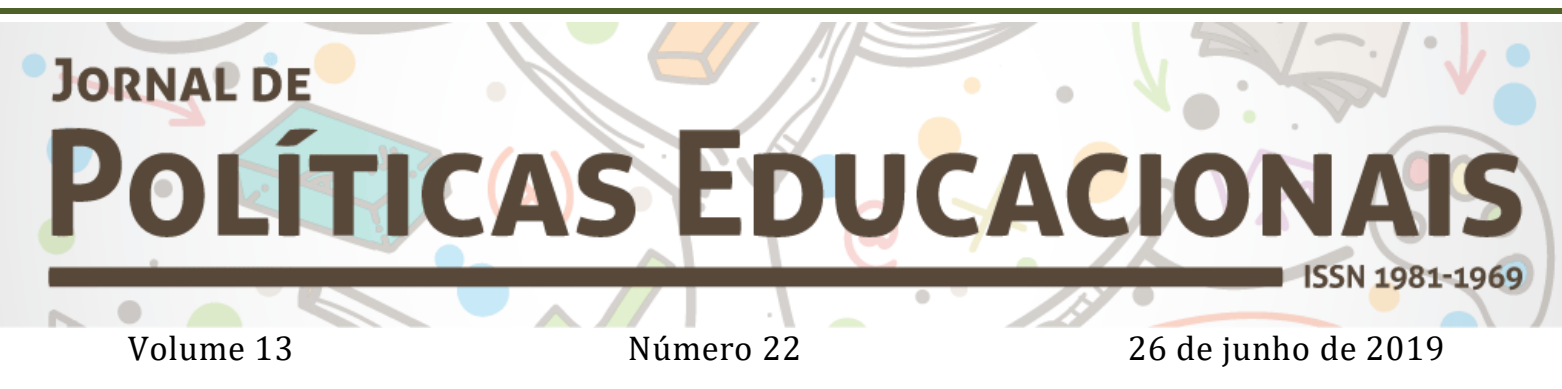

\title{
Novos parâmetros de gestão na escola pública: o perfil e os sentidos meritocráticos contidos no processo de reforma educacional na rede pública estadual de ensino de Goiás
}

\section{New management parameters in the public school: the meritocratic profile and meanings contained in the process of educational reform in the state public school system of Goiás}

\section{Nuevos parámetros de gestión en la escuela pública: el perfil y los sentidos meritocráticos contenidos en el proceso de reforma educativa en la red pública estadual de enseñanza de Goiás}

Luis Gustavo Alexandre da Silva i

Citação: SILVA, L. G. A. da. Novos parâmetros de gestão na escola pública: o perfil e os sentidos meritocráticos contidos no processo de reforma educacional na rede pública estadual de ensino de Goiás. Jornal de Políticas Educacionais. V. 13, n. 22. junho de 2019.

Resumo:

0 artigo pretende analisar questões referentes aos temas reforma educacional e gestão escolar no contexto da rede estadual de ensino de Goiás. A pesquisa origina-se da análise de documentos oficiais da Secretaria de Estado da Educação, da Cultura e do Esporte (Seduce), em especial, os relativos aos programas Pacto pela Educação, Programa Reconhecer, Sistema de Avaliação Educacional do Estado de Goiás (Saego) e Currículo-Referência e de revisão da literatura realizada por meio de investigação sistemática de dissertações e teses defendidas na área educacional sobre o tema. Para identificar com maior precisão o objeto da pesquisa, a investigação tem como base a análise dos programas governamentais descritos, cujo objetivo foi alterar o modelo de gestão, avaliação e currículo praticado na rede estadual de ensino de Goiás e compreender as consequências desse processo na condução da gestão e organização das escolas públicas.

\footnotetext{
${ }^{1}$ Doutor em Educação e professor associado na Faculdade de Educação da Universidade Federal de Goiás. luisgustavo.ufg@gmail.com
} 
SILVA, L. G. A. da. Novos parâmetros de gestão na escola pública: o perfil e os sentidos meritocárticos contidos no processo de reforma educacional na rede pública estadual de ensino de Goiás

0 resultado demonstra a influência dos conceitos de responsabilização e meritocracia nos contornos assumidos pela reforma educacional e sua inflexão sobre a gestão do sistema educativo no estado de Goiás. Palavras-chaves: Meritocracia; Reforma Educacional; Responsabilização.

\begin{abstract}
:
The article aims to analyze issues related to educational reform and school management in the context of the state education network of Goiás State, Brazil. The research originates from the analysis of official documents of the State Secretariat of Education, Culture and Sport - Seduce, in particular, those related to the Pact for Education, Recognition Program, Educational Evaluation System of the State of Goiás (Saego) and Curriculum-Reference and review of the literature carried out through systematic investigation of dissertations and theses, defended in the educational area on the subject. In order to identify more accurately the object of the research, the investigation is based on the analysis of the described government programs, whose objective was to change the management model, evaluation and curriculum practiced in the state educational network of Goiás State and to understand the consequences of this process in the conduction management and organization of public schools. The result demonstrates the influence of the concepts of accountability and meritocracy in the contours assumed by the educational reform and its inflection on the management of the educational system in the State of Goiás.
\end{abstract}

Keywords: Meritocracy; Educational Reform; Accountability.

\title{
Resumen:
}

El artículo pretende analizar cuestiones referentes a los temas reforma educativa y gestión escolar en el contexto de la red estadual de enseñanza de Goiás, Brasil. La investigación se origina del análisis de documentos oficiales de la Secretaría de Estado de Educación, Cultura y Deporte - Seduce, en especial, los relativos a los programas Pacto por la Educación, Programa Reconocer, Sistema de Evaluación Educativa del Estado de Goiás (Saego) y Currículo-Referencia y de revisión de la literatura realizada por medio de investigación sistemática de disertaciones y tesis defendidas en el área educativa sobre el tema. Para identificar con mayor precisión el objeto de la investigación, la investigación tiene como base el análisis de los programas gubernamentales descritos, cuyo objetivo fue alterar el modelo de gestión, evaluación y currículo practicado en la red estadual de enseñanza de Goiás y comprender las consecuencias de ese proceso en la conducción de la gestión y organización de las escuelas públicas. El resultado demuestra la influencia de los conceptos de responsabilización y meritocracia en los contornos asumidos por la reforma educativa y su inflexión sobre la gestión del sistema educativo en el Estado de Goiás.

Palabras claves: Meritocracia; Reforma Educativa; Rendición de cuentas.

\section{Introdução}

0 artigo pretende analisar questões referentes aos temas reforma educacional e gestão escolar, visando a apreender o movimento e as contradições inerentes à implementação, na gestão e organização da escola, de políticas públicas articuladas ao processo de reforma educacional formuladas a partir da introdução dos princípios da nova gestão pública, da reconfiguração dos procedimentos avaliativos e da reestruturação curricular.

Este estudo específico, com recorte direcionado à investigação dos temas reforma educacional e gestão escolar no contexto da rede estadual de ensino de Goiás, origina-se de análise de documentos oficiais da Secretaria de Estado da Educação, da Cultura e do 
SILVA, L. G. A. da. Novos parâmetros de gestão na escola pública: o perfil e os sentidos meritocárticos contidos no processo de reforma educacional na rede pública estadual de ensino de Goiás

Esporte (Seduce) ${ }^{2}$, em especial, os relativos aos programas Pacto pela Educação, Programa Reconhecer, Sistema de Avaliação Educacional do Estado de Goiás (Saego) e Currículo-Referência. A pesquisa também utiliza-se de revisão da literatura por meio de análise sistemática e criteriosa da produção acadêmica, em especial, dissertações e teses defendidas na área educacional sobre o tema.

Para identificar com maior precisão o objeto da pesquisa, a investigação tem como base a análise dos programas governamentais descritos, cujo objetivo foi alterar o modelo de gestão, avaliação e currículo praticado na rede estadual de ensino de Goiás e compreender as consequências desse processo na condução da gestão e organização das escolas públicas. Nesse cenário, foram levantados questionamentos sobre as reais interferências dos programas na gestão e organização das escolas públicas, bem como na melhoria do processo de ensino-aprendizagem e na composição do trabalho docente.

\section{O contexto educacional brasileiro e os índices educacionais do estado de Goiás}

Nos últimos anos, os indicadores de desempenho e os índices educacionais do estado de Goiás demonstraram significativo crescimento. Essa evolução é resultado de um progressivo processo de investimento em políticas de acesso e controle dos resultados educacionais. Essas políticas representaram um incremento no número de estabelecimentos de ensino e matrículas na educação básica. Segundo os dados do Censo Escolar 2018, no estado de Goiás existem 4.668 estabelecimentos de ensino, sendo que a Secretaria de Estado de Educação, Cultura e Esporte é responsável por 1.050 unidades escolares divididas em 981 escolas urbanas e 69 rurais (BRASIL, 2018).

A estrutura administrativa da Seduce é composta por 40 Coordenadorias Regionais de Educação, Cultura e Esporte, denominadas Crece, e o número de 20.466 professores vinculados à rede estadual de ensino (BRASIL, 2018). Em relação ao perfil da rede estadual de ensino, a Seduce mantém convênios com escolas privadas e institui o padrão de gestão militar para diversas escolas da rede. Em 2018, o número de escolas privadas conveniadas com a rede estadual atingiu a cifra de 82 unidades e o número de instituições com o padrão militar de gestão alcançou a quantidade de 56 escolas distribuídas em 42

\footnotetext{
${ }^{2}$ A atual Secretaria de Educação, Cultura e Esporte, denominada de Seduce, adquiriu esse nome em 2014, quando a Secretaria de Estado de Educação (Seduc-GO) incluiu as pastas da antiga Secretaria de Estado da Cultura (Secult-GO) e da Superintendência do Esporte e Lazer.
} 
SILVA, L. G. A. da. Novos parâmetros de gestão na escola pública: o perfil e os sentidos meritocárticos contidos no processo de reforma educacional na rede pública estadual de ensino de Goiás

municípios goianos. Salienta-se também a existência de organizações sociais responsáveis pela gestão de institutos técnicos de educação, como a escola de artes Basileu França, na capital, e instituições de ensino profissionalizante no interior do estado (GOIÁS, SEDUCE, 2019).

Em relação à quantidade de matrículas, em 2018, o número geral de alunos matriculados na educação básica em Goiás, incluindo todos os segmentos, modalidades e dependências administrativas, foi de 1.459.704. No sistema estadual de educação foram matriculados 502.166 alunos $^{3}$. A preocupação com o acesso e a matrícula na educação básica tornou-se uma política pública nos últimos anos, como demonstra a tabela 1 ao apresentar a série histórica do número de matrículas da educação básica no Brasil e por região geográfica, unidade da federação e dependência administrativa estadual nos anos de 2014 a 2018.

Tabela 1 - Matrículas de alunos na educação básica. Série histórica no Brasil e por região geográfica, unidade da federação e dependência administrativa estadual

\begin{tabular}{l|c|c|c|c}
\hline Anos & $\begin{array}{c}\text { Total de } \\
\text { matrículas - } \\
\text { Brasil }\end{array}$ & $\begin{array}{c}\text { Total de } \\
\text { matrículas - } \\
\text { Centro-Oeste }\end{array}$ & $\begin{array}{c}\text { Total de } \\
\text { matrículas - } \\
\text { Goiás }\end{array}$ & $\begin{array}{c}\text { Goiás - } \\
\text { dependência adm. } \\
\text { pública estadual }\end{array}$ \\
\hline 2014 & 49.771 .371 & 3.654 .528 & 1.440 .552 & 492.134 \\
\hline 2015 & 48.796 .512 & 3.644 .924 & 1.440 .298 & 490.006 \\
\hline 2016 & 48.817 .479 & 3.643 .646 & 1.440 .908 & 490.615 \\
\hline 2017 & 48.608 .093 & 3.639 .987 & 1.432 .261 & 478.250 \\
\hline 2018 & 48.455 .867 & 3.670 .932 & 1.459 .704 & 502.166 \\
\hline
\end{tabular}

Fonte: Sinopse da Educação Básica (BRASIL, 2014; 2015; 2016; 2017; 2018).

A análise da evolução dos índices demonstra um relativo recuo na quantidade de matrículas efetuadas na educação básica, no plano nacional. Esse cenário pode ser explicado por fatores demográficos, a melhoria do fluxo escolar e por índices de evasão ainda presentes no percurso escolar, aspectos que incrementam a necessidade de ampliar

\footnotetext{
${ }^{3}$ Os dados apresentados referem-se ao número de matrículas da educação básica divididos por localização e dependência administrativa disponíveis no site do Inep - Sinopse Estatística da Educação Básica 2018. Na Sinopse 2018, os dados da quantidade de matrículas no sistema público estão separados do sistema privado. Assim, no caso específico do sistema estadual de educação de Goiás, que possui diversos convênios com escolas privadas no conjunto da oferta de vagas disponíveis na rede de ensino, podem haver possíveis divergências entre os dados do Inep e da Seduce, pois a última contabiliza em conjunto as matrículas realizadas no sistema público e aquelas relativas às escolas privadas conveniadas ao sistema público estadual.
} 
SILVA, L. G. A. da. Novos parâmetros de gestão na escola pública: o perfil e os sentidos meritocárticos contidos no processo de reforma educacional na rede pública estadual de ensino de Goiás

o tempo de permanência dos alunos na escola com qualidade de ensino associado a políticas de distribuição de renda como elementos preponderantes a serem considerados na formulação das políticas públicas. 0 Censo Escolar 2018 registrou 48,5 milhões de matrículas nas 181,9 mil escolas de educação básica brasileiras. São 1,3 milhão estudantes a menos que em 2014, o que representa uma redução de 2,6\% em cinco anos. Só no ensino médio o número total de matrículas reduziu 7,1\%. Destaca-se a tendência de aumento dos índices de matrícula em Goiás e na dependência administrativa estadual em virtude dos investimentos financeiros do governo federal nas escolas de ensino médio em tempo integral (BRASIL, 2018).

Os índices de matrícula e desistência podem oferecer um quadro sobre a eficiência dos sistemas em garantirem o acesso e a permanência dos alunos na escola. Em relação a esse aspecto, os índices nacionais, em 2015, demonstram significativo avanço em relação ao acesso dos jovens na idade de 6 a 14 à escola, com percentual de 97,7\% de matrículas no ensino fundamental. No caso de Goiás, esse índice é ainda maior com 97,9\%, aproximando-se da totalidade de alunos matriculados nessa faixa etária. Esse é o resultado de uma intensa política de investimento público e obrigatoriedade de acesso a essa etapa de ensino instituído a duas décadas no Brasil, mas mesmo com as políticas de estímulo, os índices de conclusão do ensino fundamental no Brasil, referente a 2015, de 76\% e em Goiás de 80,6\% revelam muitos desafios a serem superados (OBSERVATÓRIO, 2018).

Salienta-se que a ausência da obrigatoriedade do acesso de crianças a toda a educação básica, durante um longo período, com prioridade durante a década de 1990 e início dos anos 2000, apenas para o ensino fundamental, significou atraso na garantia de educação aos jovens de 15 a 17 anos, etapa correspondente ao ensino médio. Nessa faixa etária houve um significativo crescimento dos dados: em 2015, o Brasil tinha 84,3\% de jovens nessa faixa etária na escola; esse número, apesar de abrangente ao incluir 8.3 milhões de jovens, ainda deixava de fora da escola 1.5 milhões de alunos. 0 ensino médio refere-se a uma etapa ainda com bastante defasagem e com baixos índices de atendimento. No Brasil, o percentual de jovens de 15 a 17 matriculados no ensino médio é de 62,7\% e em Goiás 66\%, mas a quantidade de jovens de 19 anos que concluem essa etapa revela uma grande defasagem no Brasil com 58,5\%, e em Goiás com 61,5\%, em 
SILVA, L. G. A. da. Novos parâmetros de gestão na escola pública: o perfil e os sentidos meritocárticos contidos no processo de reforma educacional na rede pública estadual de ensino de Goiás

2015. Isso revela que cerca de $40 \%$ dos jovens matriculados não completam essa etapa da educação básica (OBSERVATÓRIO, 2018).

Os índices de distorção idade-série também revelam as limitações das políticas públicas de investimento no efetivo aprendizado dos alunos. A tabela 2 demonstra esses índices de distorção idade-série no Brasil e Goiás.

Tabela 2 - Taxa de distorção idade-série

\begin{tabular}{c|c|c|c|c}
\hline Local & Ano & $\begin{array}{c}\text { Ensino fundamental } \\
\text { anos iniciais } \\
\text { (6 a 14 anos) }\end{array}$ & $\begin{array}{c}\text { Ensino fundamental } \\
\text { anos finais }\end{array}$ & $\begin{array}{c}\text { Ensino médio } \\
\text { (15 a 17 anos) }\end{array}$ \\
\hline Brasil & 2017 & $12 \%$ & $25,9 \%$ & $28,2 \%$ \\
\hline Goiás & 2017 & $8,6 \%$ & $21,1 \%$ & $22,6 \%$ \\
\hline
\end{tabular}

Fonte (OBSERVATÓRIO, 2018)

É possível perceber um avanço no acesso ao ensino fundamental e a ampliação dos índices relativos ao ensino médio, mas, em contrapartida, a distorção idade-série continua sendo um grave problema de política educacional a ser resolvido. Para além dos elementos econômicos relativos à regularização do fluxo escolar, que representa investimentos duplicados dos governos para manter o aluno na escola e criar novas vagas para acolher os ingressantes, a distorção idade-série revela sérios problemas sociais e pedagógicos ao demonstrar a dificuldade dos alunos de seguirem um percurso contínuo de escolarização.

Com o objetivo de acompanhar a melhoria do desempenho dos alunos na educação básica, foi formulado pelo governo federal o Índice de Desenvolvimento da Educação Básica (Ideb). Esse índice, considerado pelos governos como a principal política de aferição da qualidade, pode demonstrar alguns elementos a respeito das políticas educacionais. A tabela 3 nos mostra a evolução do Ideb no Brasil e Goiás.

Tabela 3 - Evolução do índices de desenvolvimento da educação básica - Brasil e Goiás

\begin{tabular}{c|l|l|l|l|l}
\hline \multicolumn{2}{c|}{$\begin{array}{c}\text { Anos iniciais do ensino } \\
\text { fundamental }\end{array}$} & \multicolumn{2}{c|}{$\begin{array}{c}\text { Anos finais do ensino } \\
\text { fundamental }\end{array}$} & \multicolumn{2}{c}{ Ensino médio } \\
\hline Ideb Brasil & Ideb Goiás & Ideb Brasil & Ideb Goiás & Ideb Brasil & $\begin{array}{l}\text { Ideb } \\
\text { Goiás }\end{array}$ \\
\hline $2005=\mathbf{3 , 8}$ & $2005=\mathbf{4 , 1}$ & $2005=\mathbf{3 , 5}$ & $2005=\mathbf{3 , 5}$ & $2005=\mathbf{3 , 4}$ & $\begin{array}{l}2005= \\
\mathbf{3 , 2}\end{array}$ \\
\hline
\end{tabular}


SILVA, L. G. A. da. Novos parâmetros de gestão na escola pública: o perfil e os sentidos meritocárticos contidos no processo de reforma educacional na rede pública estadual de ensino de Goiás

\begin{tabular}{l|l|l|l|l|l}
\hline \hline $2007=4,2$ & $2007=4,3$ & $2007=3,8$ & $2007=3,8$ & $2007=3,5$ & $2007=3,1$ \\
\hline $2009=4,6$ & $2009=4,9$ & $2009=4,0$ & $2009=4,0$ & $2009=3,6$ & $2009=3,4$ \\
\hline $2011=5,0$ & $2011=5,3$ & $2011=4,1$ & $2011=4,2$ & $2011=3,7$ & $2011=3,8$ \\
\hline $2013=5,2$ & $2013=5,7$ & $2013=4,2$ & $2013=4,7$ & $2013=3,7$ & $2013=4,0$ \\
\hline $2015=5,5$ & $2015=5,8$ & $2015=4,5$ & $2015=4,9$ & $2015=3,7$ & $2015=3,9$ \\
\hline $2017=\mathbf{5 , 8}$ & $2017=\mathbf{6 , 1}$ & $2017=\mathbf{4 , 7}$ & $2017=\mathbf{5 , 3}$ & $2017=\mathbf{3 , 8}$ & $\begin{array}{l}2017= \\
\mathbf{4 , 3}\end{array}$ \\
\hline
\end{tabular}

Fonte: BRASIL, MEC, INEP, 2017a

A análise dos dados da tabela demonstra que a Seduce realiza um significativo trabalho de acompanhamento, controle e investimento na melhoria dos índices educacionais. No entanto, ressalta-se a dificuldade de conduzir um efetivo processo de melhoria dos índices do Ideb no ensino médio, pois tanto os percentuais nacionais como os goianos demonstram os baixos resultados nessa etapa comparados com os dados relativos aos anos iniciais do ensino fundamental. Esses números podem ser resultado do baixo investimento público na infraestrutura das escolas da rede estadual de ensino, aspecto determinante na formação dos alunos. Em Goiás, somente 85\% das escolas possuem biblioteca, 70\% laboratórios de informática, 20\% laboratórios de ciências, 66\% quadras de esportes e $12 \%$ salas de leitura. Acrescenta-se a isso a quantidade de professores com contratos temporários. Em relação ao tipo de vínculo empregatício dos docentes da rede pública estadual de ensino, a configuração é constituída por 10.109 docentes com contrato temporário, 45 docentes com contrato terceirizado e 70 docentes com contrato CLT, de um total de 20.466 professores (BRASIL, 2018).

Atualmente, os governos federais e estaduais realizam um significativo esforço para ampliar o tempo de permanência das crianças na escola e na formulação de programas voltados para a melhoria da aprendizagem inseridos na proposta de educação de tempo integral. Todavia as políticas públicas de escolas de tempo integral não avançaram muito no país, apesar de esforços realizados em sua expansão, em especial, durante os anos de 2011 a 2015, em que o índice nacional chegou a 16,8\% de matriculados. Em 2016, esse percentual sofre uma significativa queda ao atingir a cifra de 11,6\% e, em 2017, uma relativa alta com 15,5\% de matriculados (OBSERVATÓRIO, 2018).

De acordo com o Censo Escolar 2018, as matrículas no ensino integral representavam $9,5 \%$ do total de estudantes matriculados no ensino médio. 0 aumento das matrículas em tempo integral é decorrente dos investimentos financeiros oriundos do Programa de Fomento à Implantação das Escolas de Ensino Médio em Tempo Integral. 
SILVA, L. G. A. da. Novos parâmetros de gestão na escola pública: o perfil e os sentidos meritocárticos contidos no processo de reforma educacional na rede pública estadual de ensino de Goiás

No entanto, as matrículas em tempo integral no ensino fundamental reduziram entre 2017 e 2018. Salienta-se que a principal ação, no campo pedagógico, formulada pelo governo federal para subsidiar as escolas de tempo integral, foi o Programa Mais Educação (BRASIL, 2018). Apesar dos esforços, a ausência de um projeto formativo de referência nacional para a educação integral restringiu as possibilidades educativas do programa. Além disso, acrescenta-se também as precárias condições estruturais das escolas, a descontinuidade dos repasses de recursos públicos, a ausência das contrapartidas municipais, as limitações do currículo escolar relativo às atividades do programa, a ausência de profissionais capacitados para a realização das atividades pedagógicas propostas etc. (BRASIL, 2017b; SILVA, 2015).

\section{0 processo de implementação da reforma educacional em Goiás: programas e ações}

A reforma educacional iniciou-se no estado de Goiás no ano de 2011, no governo de Marconi Perillo (2010-2014), com a divulgação do documento Pacto pela Educação Um futuro melhor exige mudanças e a implementação de suas ações no campo das políticas públicas educacionais. O Pacto pela Educação contém um conjunto de diretrizes e orientações, visando ao redimensionamento dos princípios relativos à gestão, ao currículo e ao processo de avaliação realizados na estrutura educacional do sistema estadual de educação (GOIAS.SEDUCE, 2011). 0 documento institui uma nova perspectiva teórica que deve orientar a educação estadual, a saber, a responsabilização $e$ a meritocracia. Esses princípios aparecem como o eixo fundamental para o conjunto das políticas educacionais, com o objetivo de instituir um novo sentido na gestão do trabalho pedagógico, no currículo escolar, na avaliação dos alunos e na profissionalização docente.

O Pacto pela Educação efetiva-se como política pública ao difundir cinco eixos e 25 ações com impacto efetivo na gestão e organização da escola4. 0 documento constitui-se como a principal referência concernente ao processo de reforma educacional em Goiás e a partir de seus fundamentos foram elaborados programas e iniciativas educacionais como o Programa Reconhecer (2011), o Saego (2011) e o Currículo Referência (2013).

\footnotetext{
${ }^{4} 0$ primeiro eixo intitula-se valorizar e fortalecer o profissional da educação. 0 segundo eixo intitula-se adotar práticas de ensino de alto impacto no aprendizado. 0 terceiro eixo intitula-se reduzir significativamente a desigualdade educacional. 0 quarto eixo intitula-se estruturar o sistema de reconhecimento e remuneração por mérito. 0 quinto eixo intitula-se realizar reforma na gestão e na infraestrutura da rede estadual de ensino (GOIAS.SEDUCE, 2011).
} 
SILVA, L. G. A. da. Novos parâmetros de gestão na escola pública: o perfil e os sentidos meritocárticos contidos no processo de reforma educacional na rede pública estadual de ensino de Goiás

O Programa Reconhecer instituiu a política de bônus na estrutura do sistema estadual de educação. A intenção inicial descrita nas leis que definiram o pagamento de bônus de incentivo aos profissionais da educação era estimular o trabalho de regência de sala de aula e, por esse motivo, previa o pagamento de remuneração adicional aos professores da educação básica a partir do critério de assiduidade e de entrega quinzenal do plano de ensino 5 . Nos anos subsequentes à criação do bônus para o pagamento dos professores, a secretaria estadual de educação definiu para o grupo gestor da escola um índice de acompanhamento da gestão que incluiu, entre outros critérios, o controle do trabalho realizado pelos professores regentes e coordenadores pedagógicos, em especial, no que concerne à assiduidade e à entrega dos planos de aulas, além de definir como responsabilidade desse grupo o lançamento da frequência dos profissionais da educação no sistema interno de controle da gestão escolar, aspectos considerados obrigatórios para o recebimento do bônus de incentivo salarial (GOIAS, 2013).

No entanto, esse processo de descentralização administrativa e financeira articulada aos parâmetros da nova gestão pública somente desenvolve-se plenamente com a criação das políticas de avaliação em larga escala capazes de definir objetivos de proficiência para o desempenho dos alunos e escolas. No caso do estado de Goiás, foi formulado o Sistema de Avaliação Educacional do Estado de Goiás (Saego), em 2011, com o objetivo de produzir diagnósticos sobre o nível de proficiência dos alunos matriculados na rede estadual de ensino e nas escolas particulares conveniadas. Em geral, o Saego mantém o mesmo desenho de avaliação do Sistema de Avaliação da Educação Básica (Saeb), com a diferença de avaliar anualmente os alunos do $2^{\circ}$ ano do ensino fundamental em Língua Portuguesa e os alunos do 5o e 9o anos do ensino fundamental e do $3^{\text {o }}$ ano do ensino médio em Língua Portuguesa e Matemática. Para o desenvolvimento pedagógico dos alunos da educação básica foi criada também, pela Seduce, a avaliação dirigida amostral (ADA), com periodicidade bimestral e característica diagnóstica, visando a acompanhar o desempenho escolar dos alunos nas disciplinas de Língua Portuguesa, Matemática e Ciências da Natureza (GOIÁS. SEDUCE, 2015).

\footnotetext{
${ }^{5}$ A partir do ano de 2012, a Seduc-GO ampliou o número de profissionais da educação beneficiados pelo Programa Reconhecer ao incluir no pagamento do bônus os coordenadores pedagógicos, o grupo gestor e os tutores pedagógicos.
} 
SILVA, L. G. A. da. Novos parâmetros de gestão na escola pública: o perfil e os sentidos meritocárticos contidos no processo de reforma educacional na rede pública estadual de ensino de Goiás

Todas essas medidas corroboram com a melhoria do desempenho dos alunos no Índice de Desenvolvimento da Educação Goiana (Idego), obtido a partir dos resultados anuais da Prova Goiás, componente do Saego, com os índices de fluxo escolar da rede pública estadual de ensino. 0 Idego foi formulado a partir do processo de reforma educacional constituída pelo Pacto pela Educação, com o objetivo de identificar o nível de proficiência dos alunos da educação básica nas disciplinas de Língua Portuguesa e Matemática e acompanhar o desenvolvimento dos alunos a longo prazo nos processos de avaliação.

Nesse contexto, a matriz curricular desempenha um papel essencial para coordenar a ação dos docentes e os esforços visando a atingir os melhores resultados avaliativos. Assim, a Seduce elaborou, em 2012, o Currículo-Referência cujo objetivo foi definir os conteúdos, o foco e as habilidades a serem trabalhadas pelos professores nas escolas públicas. O Currículo-Referência organiza-se a partir de uma lógica bimestral, o que significa que os professores devem se orientar por um procedimento sequencial na abordagem dos conteúdos e organizar o trabalho pedagógico aos parâmetros da avaliação dirigida amostral (ADA). Apesar de as orientações do documento curricular envolverem o conjunto das disciplinas oferecidas na educação básica, destaca-se a preocupação da Seduce com os conteúdos e habilidades exigidas nos testes avaliativos nacionais (GOIAS. SEDUCE, 2012).

Para efetivar na sala de aula as orientações contidas no Currículo Referência, foram elaborados os cadernos de aprendizagem denominados Aprender mais. Esses cadernos de atividades funcionam como material pedagógico complementar aos livros didáticos utilizados pelos professores nas disciplinas de Língua Portuguesa e Matemática, em comum acordo com os conteúdos sistematizados pelo currículo e as demandas dos procedimentos avaliativos. Os cadernos Aprender mais, lançados no início de 2017, são direcionados aos alunos dos $5^{0}$ e $9^{0}$ anos do ensino fundamental e da $3^{\text {a }}$ série do ensino médio, com o objetivo de direcionar o trabalho pedagógico realizado pelo professor em sala de aula.

\section{Reforma educacional no estado de Goiás: análise das pesquisas}

Esta parte do artigo apresenta os resultados de pesquisas acadêmicas produzidas 
SILVA, L. G. A. da. Novos parâmetros de gestão na escola pública: o perfil e os sentidos meritocárticos contidos no processo de reforma educacional na rede pública estadual de ensino de Goiás

sobre os temas reforma educacional e gestão escolar no contexto da rede estadual de ensino de Goiás.

Em geral, as pesquisas revelam que a reforma educacional realizada em Goiás, por meio do Pacto pela Educação, intensificou a perda de direitos adquiridos pelos professores da rede estadual de ensino, condicionando-os a uma situação de maior desprofissionalização e precarização nas condições de trabalho. Os trabalhos de Alves (2015) e Araújo Júnior (2013) analisam as mudanças no mundo do trabalho e seus efeitos sobre o trabalho docente, em especial, como essas alterações representaram grande dificuldade para o Sindicato dos Trabalhadores em Educação de Goiás (Sintego) conseguir agregar os professores em torno da defesa dos direitos e do combate ao processo de privatização em curso na rede estadual de ensino de Goiás ${ }^{6}$.

Nessa mesma linha, Pessoni (2017) demonstra que o processo de reforma educacional conduzido no estado de Goiás articula-se a uma concepção de educação defendida pelos organismos internacionais, em especial, o Banco Mundial e a Unesco. Essas instituições articuladas aos interesses do capital internacional difundiram, por meio de documentos e conferências, uma visão definida a respeito do processo de descentralização da gestão escolar, das avaliações de larga escala, dos currículos nacionais articulados a procedimentos avaliativos e dos critérios de qualidade associados à avaliação.

Em relação aos efeitos da reforma educacional na gestão e organização da escola, Silva (2014) revela as repercussões das políticas contidas no Pacto pela Educação, na gestão da escola e no processo de ensino aprendizagem. A autora analisa em sua pesquisa os desdobramentos da forte influência da perspectiva de educação defendida pelos organismos internacionais na política educacional do Estado e a presença de organizações não governamentais na implementação de estratégias reformistas. Segundo a autora, determinados aspectos articulam-se, como o programa de reconhecimento e remuneração por mérito, que fortalece práticas de controle e punição na escola, a implementação combinada de políticas avaliativas e curriculares e a redução da autonomia pedagógica dos professores na realização do trabalho.

\footnotetext{
${ }^{6}$ As pesquisas de Carmo (2014) e Almeida (2018) também analisam o processo de reestruturação produtiva, a concepção de estado presente na transição para o neoliberalismo e seus efeitos sobre a precarização do trabalho do professor em Goiás.
} 
SILVA, L. G. A. da. Novos parâmetros de gestão na escola pública: o perfil e os sentidos meritocárticos contidos no processo de reforma educacional na rede pública estadual de ensino de Goiás

Nesse contexto, o trabalho de Moura (2016) analisa os efeitos indutivos do Programa Reconhecer e do Prêmio Poupança-aluno, de reconhecimento e remuneração por mérito, na constituição dos valores da meritocracia, da competitividade, da responsabilização, do controle por incentivo/punição presentes na reforma educacional. Segundo a autora, esse movimento contido no processo de reforma contém uma perspectiva neotecnicista de educação ao disseminar uma visão de educação sedimentada sobre os princípios da racionalização das práticas educativas submetidas a procedimentos de avaliação de larga escala.

$\mathrm{Na}$ realidade, há diversos trabalhos que analisam a reforma educacional e as articulações com o sistema de avaliação em larga escala instituídos na rede estadual de ensino, bem como as consequências para o processo de aprendizado dos alunos e a autonomia dos professores.

O estudo realizado por Melo (2018) com diretores escolares da rede estadual de ensino mostra a percepção dos dirigentes a respeito das alterações no cotidiano escolar após o crescimento dos procedimentos de avaliação em larga escala instituído nas escolas. A pesquisa demonstrou que o Índice de Desenvolvimento da Educação Básica (Ideb) provocou diversas mudanças na gestão escolar e a constante preocupação dos diretores em executar ações com vistas a atingir as metas projetadas pelo Instituto Nacional de Estudos e Pesquisas Educacionais (Inep) e estabelecidas pela Seduce. Na prática, as avaliações de larga escala projetadas pelo governo nacional e estadual comprometeram a autonomia dos diretores escolares, em especial, por induzirem os conteúdos definidos nas matrizes de referência e instituir o ranqueamento das escolas públicas.

Nesse mesmo sentido, Fernandes (2015) esclarece que as políticas educacionais promovidas pela Seduce, em especial, por meio do Pacto pela Educação e do Sistema de Avaliação Educacional do Estado de Goiás (Saego), baseadas em avaliações de larga escala e em resultados, promovem um esvaziamento do currículo escolar ao estabelecerem a padronização das relações de ensino-aprendizagem com base em competências e habilidades. Segundo a autora, as consequências são prejudiciais aos professores, que têm sua autonomia pedagógica comprometida, e aos alunos, que têm o processo de ensinoaprendizagem restrito à preparação para a realização de testes sistêmicos.

Os trabalhos de Costa (2014) e Medeiros (2013) analisam a cultura de avaliação classificatória instituída no cotidiano escolar por meio da Avaliação Diagnóstica Amostral 
SILVA, L. G. A. da. Novos parâmetros de gestão na escola pública: o perfil e os sentidos meritocárticos contidos no processo de reforma educacional na rede pública estadual de ensino de Goiás

(ADA), que contém a perspectiva de preparar os alunos, por meio de exames bimestrais, para as avaliações de larga escala, como a Prova Goiás e a Prova Brasil. As autoras salientam os efeitos das avaliações bimestrais com forte conotação classificatória, sem a devida preocupação com a formação dos professores, no que concerne ao reforço da tradicional perspectiva de avaliação contida nas provas, seus efeitos sobre currículo escolar e os impactos nas relações de ensino-aprendizagem, bem como os desdobramentos relativos à intensificação do controle sobre o trabalho docente.

Há trabalhos que apresentam um posicionamento crítico concernente às políticas educacionais implementadas na rede estadual de ensino, em especial, as instituídas pelo Currículo Referência destinado a constituir um padrão curricular articulado às diretrizes avaliativas, com significativo impacto na organização e gestão dos sistemas públicos de ensino.

Os estudos de Matos (2018) revelaram que a formulação do Currículo Referência não contou com a efetiva participação dos professores em seu processo de elaboração. Assim, o documento aparece para os docentes com forte conotação arbitrária e articulada aos procedimentos de avaliação. Segundo Silva (2018a), o Currículo Referência é um texto curricular prescritivo, estruturado na lógica da teoria tradicional do currículo, que se materializa de diferentes formas e com amarras institucionais obrigatórias para sua utilização. Segundo a autora, a implementação do Currículo Referência segue procedimentos capazes de assegurar o mais absoluto controle do trabalho docente, com envolvimento e cobrança de resultados por parte da Seduce.

O trabalho de Silva (2018b) realiza uma significativa análise dos itens contidos nos cadernos do Projeto Aprender mais, elaborado pela Seduce. 0 estudo investigou 72 itens no caderno do $1^{\underline{0}}$ bimestre e 64 itens no caderno do $2^{\mathrm{o}}$ bimestre, relativos aos cadernos de Matemática da terceira série do ensino médio. Segundo Silva (2018b), apesar de a estrutura do Currículo Referência definir os conteúdos a serem trabalhados pelos professores a partir de uma organização bimestral, alguns itens contidos nos cadernos do Aprender mais não constam na bimestralização, o que causa um problema para os docentes seguirem os itens dos cadernos e os conteúdos definidos pelo currículo. Outro aspecto demonstrado na pesquisa, dentre outros, é que a comunidade escolar realiza diversas atividades de revisão dos conteúdos e simulados de provas nacionais com materiais enviados pela própria Seduce, com o intuito de treinar os alunos. Por fim, a 
SILVA, L. G. A. da. Novos parâmetros de gestão na escola pública: o perfil e os sentidos meritocárticos contidos no processo de reforma educacional na rede pública estadual de ensino de Goiás

pesquisa esclarece que a maioria dos itens dos cadernos obedecem a uma lógica convencional de organização do conhecimento e poucos foram formulados a partir das recomendações das Diretrizes Curriculares Nacionais para o ensino médio, que defende uma perspectiva contextualizada para a organização dos conteúdos e do conhecimento nessa etapa da educação básica.

\section{Considerações finais}

Os trabalhos analisados demonstram as repercussões e as críticas ao processo de reforma educacional realizada no estado de Goiás, por meio do Pacto pela Educação. As pesquisas revelam uma perspectiva neotecnicista de educação contida nos contornos da reforma, ao disseminar uma visão de educação sedimentada sobre os princípios da responsabilização e da meritocracia materializados por meio da avaliação classificatória, do currículo padronizado e da competitividade entre os agentes escolares.

Os estudos empreendidos permitiram identificar como os programas conduzidos pela Seduce articulam-se entre si com o objetivo de disseminar esses princípios. 0 Programa Reconhecer, com o pagamento de bônus e a intensificação do controle das atividades pedagógicas, o Saego, com o estímulo às avaliações de larga escala e o Currículo Referência, com a padronização da matriz associada às bases avaliativas nacionais definidas pela Saeb, tendem a induzir uma lógica de controle e vigilância das ações pedagógicas realizadas pelos agentes escolares.

Esse cenário demonstra que os contornos assumidos pelas reformas educacionais e sua inflexão na área da gestão educacional contêm significativa influência do setor privado e de sua forma de regulação. Em razão das contradições contidas no processo educativo e da disputa política existente na sociedade, a possibilidade de enfraquecer essa tendência de disseminação de princípios de mercado na esfera pública passa pela formulação de um projeto educativo mais orgânico e sistêmico, o que demanda a rediscussão do processo de cofinanciamento do setor privado com recursos públicos, o redimensionamento do poder de grupos privados nas principais esferas de decisões de políticas educacionais e a reavaliação dos parâmetros privados de gestão transferidos para as instituições educativas, aspectos essenciais para restabelecer sobre bases mais sólidas e duradouras o papel do Estado e da sociedade civil organizada como agentes 
SILVA, L. G. A. da. Novos parâmetros de gestão na escola pública: o perfil e os sentidos meritocárticos contidos no processo de reforma educacional na rede pública estadual de ensino de Goiás

indutores de políticas educacionais e restituir os fundamentos da educação pública, laica e gratuita para todos.

\section{Referências}

ALMEIDA, Rosivaldo Pereira de. Armadilhas no labirinto: escolarização e trabalho docente desafiados pelo Pacto da Educação em Goiás. 2018. 221f. Tese (Doutorado). Programa de Pós-Graduação em Educação - Faculdade de Educação da Universidade Federal de Goiás, Goiânia, 2018.

ALVES, Cleudimar Rosa. Políticas públicas educacionais: a reestruturação produtiva do capital e o Pacto pela Educação em Catalão Goiás. 2015. 160f. Dissertação (Mestrado) Programa de Pós-Graduação Strictu Sensu em Geografia da Universidade Federal de Goiás. Regional Catalão. Catalão, 2015.

ARAÚJO JÚNIOR, João Ferreira de. 0 trabalhador da educação e a acumulação flexível do capital: um estudo do posicionamento do Sintego frente à política educacional de Goiás. 2013. 128f. Dissertação (Mestrado). Programa de Pós-Graduação em Educação, Universidade Federal de Goiás. Goiânia, 2013.

BRASIL.MEC.INEP. Índice de Desenvolvimento da Educação Básica. Brasília, 2017a. Disponível em

http://ideb.inep.gov.br/resultado/resultado/resultado.seam?cid=1184542. . Acesso em 10/10/2017.

BRASIL.MEC.INEP. Sinopse Estatística da Educação Básica. Brasília, 2014. Disponível em http://portal.inep.gov.br/sinopses-estatisticas-da-educacao-basica. Acesso em $\underline{10 / 10 / 2018 .}$

BRASIL.MEC.INEP. Sinopse Estatística da Educação Básica. Brasília, 2015. Disponível em http://portal.inep.gov.br/sinopses-estatisticas-da-educacao-basica. Acesso em $10 / 10 / 2018$.

BRASIL.MEC.INEP. Sinopse Estatística da Educação Básica. Brasília, 2016. Disponível em http://portal.inep.gov.br/sinopses-estatisticas-da-educacao-basica. Acesso em $10 / 10 / 2018$.

BRASIL.MEC.INEP. Sinopse Estatística da Educação Básica. Brasília, 2017. Disponível em http://portal.inep.gov.br/sinopses-estatisticas-da-educacao-basica. Acesso em $10 / 10 / 2018$

BRASIL.MEC.INEP. Sinopse Estatística da Educação Básica. Brasília, 2018. Disponível em http://portal.inep.gov.br/sinopses-estatisticas-da-educacao-basica. Acesso em 04/02//2019 
SILVA, L. G. A. da. Novos parâmetros de gestão na escola pública: o perfil e os sentidos meritocárticos contidos no processo de reforma educacional na rede pública estadual de ensino de Goiás

BRASIL. Senado Federal. Relatório no 19, de 2015- Comissão de Educação, Cultura e Esporte - CE de Avaliação de Políticas Públicas sobre Educação em tempo integral (Programa Mais Educação). Disponível em: www19.senado.gov.br/sdleggetter/.../77b9a117-5af4-4200-85a1-69f739350a89. Acesso em 10/10/2017b.

CARMO, Rafael Moreira do Carmo. Políticas Educacionais no Ensino Médio e seus efeitos sobre o trabalho docente no Estado de Goiás. 2014. 259f. Dissertação (Mestrado) Programa de Pós-Graduação em Sociologia da Faculdade de Ciências Sociais da Universidade Federal de Goiás,2014.

COSTA, Rosângela do Nascimento. Impactos da avaliação diagnóstica nas aulas de Língua Portuguesa das escolas de Quirinópolis-Goiás. 2014. 139f. Dissertação (Mestrado) - Universidade Federal de Goiás, Faculdade de Letras (FL) - Programa de Pós-Graduação em Letras e Linguística, Goiânia, 2014.

FERNANDES, Silvia Reis. Concepções e práticas vigentes em escolas públicas: a influência das políticas educacionais no trabalho dos professores.2015. 108f. Dissertação (Mestrado) - Pontifícia Universidade Católica de Goiás, Programa de PósGraduação Stricto Sensu em Educação, Goiânia, 2015.

GOIÁS. Lei no 18.093 de 17 de Julho de 2013. Institui, para o ano de 2013, o Bônus de Incentivo Educacional aos profissionais da educação pública estadual e dá outras providência.

GOIÁS. SEDUCE. Site oficial da Secretaria de Estado de Educação, Cultura e Esporte. Escolas detalhadas. https://site.seduce.go.gov.br/pesquisa-de-escolas-detalhada/ acesso em 21/03/2019.

GOIÁS. SEDUCE. CAEd. Revista do Sistema de Avaliação. SAEGO. Universidade Federal de Juiz de Fora, Faculdade de Educação, Juiz de Fora, 2015. Disponível em http://www.saego.caedufjf.net/ acesso em 08/02/2019.

GOIAS. SEDUCE. Pacto pela Educação: um futuro melhor exige mudanças. 2011. Disponível em http://www.seduc.go.gov.br/especiais/pactopelaeducacao/docs/Microsoft PowerPoint. Acesso em 08/02/2019.

GOIAS. SEDUCE. Currículo Referência da Rede Estadual de Educação de Goiás. 2012. http://www.seduc.go.gov.br/imprensa/documentos/arquivos/CurriculoReferencia. Acesso em 08/02/2019.

MATOS, Milena de Oliveira. 0 Currículo e o seu papel no ensino: compreensão de docentes de Ciências da Natureza do Ensino Fundamental II das Escolas Estaduais em Goiânia. 2018. 122f. Dissertação (Mestrado) Programa de Pós-Graduação em Educação em Ciências e Matemática - Universidade Federal de Goiás, 2018.

MEDEIROS, Daniela Silva Mendes. A avaliação diagnóstica da Secretaria da Educação do Estado de Goiás: das intenções às ações. 2013. 96f. Dissertação (Mestrado) 
SILVA, L. G. A. da. Novos parâmetros de gestão na escola pública: o perfil e os sentidos meritocárticos contidos no processo de reforma educacional na rede pública estadual de ensino de Goiás

Programa de Pós-Graduação em Educação em Ciências e Matemática. Universidade Federal de Goiás, 2013.

MELO, Viviane Pereira da Silva. Avaliação em larga escala: repercussões do IDEB na visão dos diretores de escola da rede estadual de Goiás. 2018. 182 f. Dissertação (Mestrado). Programa de Pós-Graduação em Educação - Faculdade de Educação da Universidade Federal de Goiás, Goiânia, 2018.

MOURA, Priscila de Oliveira. O Sistema de bônus/prêmio na reforma Pacto pela Educação (Seduc/Goiás 2011-2014). 2016. 112f. Dissertação (Mestrado) - Programa de Pós-Graduação em Educação - Faculdade de Educação da Universidade Federal de Goiás, Goiânia, 2016.

OBSERVATORIO. Observatório do PNE. http://www.observatoriodopne.org.br. Acesso em $20 / 12 / 2018$

PESSONI, Lucineide Maria de Lima. Internacionalização das políticas educacionais, finalidades educativas escolares e qualidade de ensino: a reforma educativa no Estado de Goiás. 2017. 211f. Tese (Doutorado) - Programa de Pós-Graduação Stricto Sensu em Educação Pontifícia Universidade Católica de Goiás. Goiânia, 2017.

SILVA, Simonia Peres da. 0 processo de implementação das políticas educacionais e repercussões nas formas de gestão da escola e no processo de ensinoaprendizagem: o Pacto pela Educação em Goiás. 2014. 249f. Tese (Doutorado) Pontifícia Universidade Católica de Goiás, Programa de Pós-Graduação em Educação, Goiânia, 2014.

SILVA, Ana Paula Gomes Vieira. 0 Currículo Referência da rede estadual de educação de Goiás: implicações nas atividades de professores de Ciências. 2018. 150f. Dissertação (Mestrado). Programa de Pós-graduação em Educação em Ciências e Matemática. Universidade Federal de Goiás. Goiânia, 2018a.

SILVA, Cleuton Martins. Projeto Aprender+: Uma Análise dos Itens de Matemática nos cadernos dos $1^{\circ}$ e 2ํㅡㄹ Bimestres em Relação ao Desenvolvimento de Competências e Habilidades.2018. 206f. Dissertação (Mestrado). Programa de Mestrado Profissional em Matemática em Rede Nacional. Unidade Acadêmica Especial de Matemática e Tecnologia - Regional Catalão da Universidade Federal de Goiás. Catalão, 2018b.

SILVA, Luís Gustavo A; SAMPAIO, César Luis. Trabalho e autonomia do coordenador pedagógico no contexto das políticas públicas educacionais implementadas no Estado de Goiás. Ensaio: aval.pol.públ.Educ. [Online]. 2015, vol.23, n.89, pp.964-983. 
SILVA, L. G. A. da. Novos parâmetros de gestão na escola pública: o perfil e os sentidos meritocárticos contidos no processo de reforma educacional na rede pública estadual de ensino de Goiás
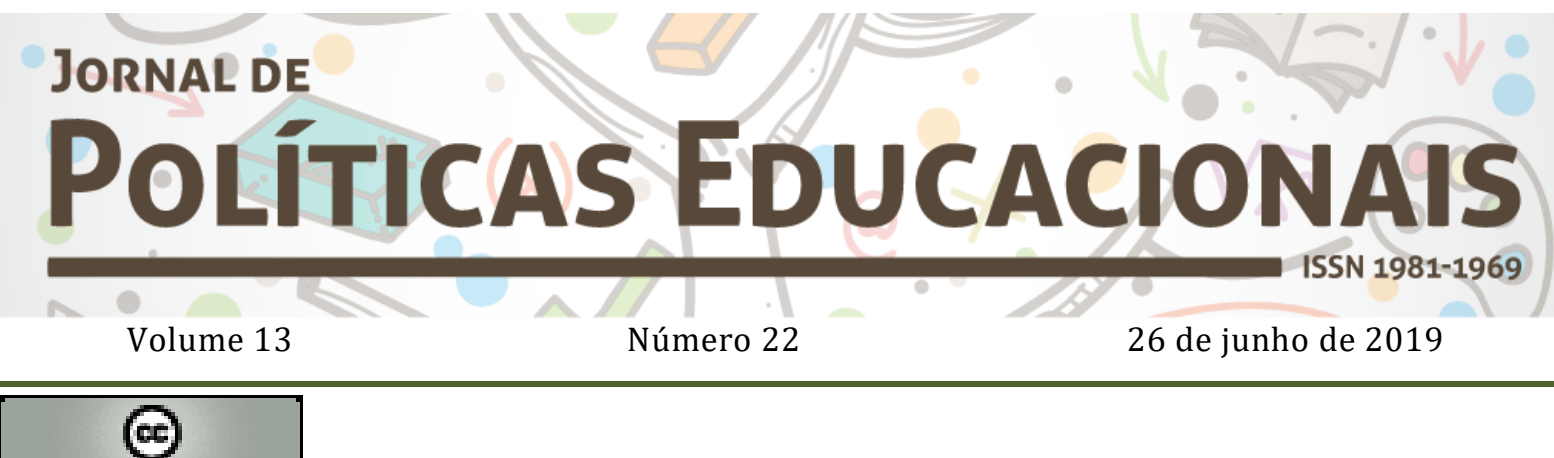

SORERIGHISRESERVED O Copyright é retido pelo/a autor/a (ou primeiro coautor) que outorga o direito da primeira publicação ao Jornal de Políticas Educacionais. Mais informação da licença de CreativeCommons encontram-se em http://creativecommons.org/licenses/by-nc-nd/2.5. Qualquer outro uso deve ser aprovado em conjunto pelo/s autor/es e pelo periódico.

JoRnal De Políticas EduCACIONAIS é uma publicação do Núcleo de Políticas Educacionais do Setor de Educação da Universidade Federal do Paraná - NuPE/UFPR, em consórcio com a Linha de Pesquisa em Políticas Educacionais do Programa de Pós-Graduação em Educação - PPGE/UFPR, que aceita colaboração, reservando-se o direito de publicar ou não o material espontaneamente enviado à redação. As colaborações devem ser enviadas ao NuPE/UFPR, conforme orientações contidas nas páginas do periódico na internet: http://revistas.ufpr.br/jpe.

\author{
Indexação: \\ BBE - Biblioteca Brasileira de Educação (MEC/INEP) \\ Clase (Base de Datos Bibliográfica de Revistas de Ciencias Sociales y Humanidades) \\ Diadorim - Diretório de Política de Acesso Aberto das Revistas Científicas Brasileiras (IBICT) \\ Google Scholar \\ Index Copernicus \\ Portal de Periódicos (CAPES) \\ SER - Sistema Eletrônico de Revistas da Universidade Federal do Paraná (SER/UFPR) \\ Sumários de Revistas Brasileiras (FUNPEC-RP) \\ DRII - Directory of Research Journals Indexing
}

(Periódico integralmente disponível apenas em via eletrônica)

Jornal de Políticas Educacionais / Núcleo de Políticas Educacionais da Universidade Federal do Paraná -

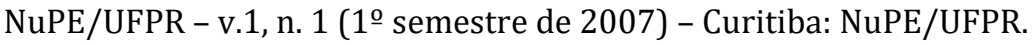

Volume 13, número 22 - Junho de 2019

ISSN 1981-1969

1. Educação - Periódicos. 2. Política Educacional - Periódicos. I. NuPE/UFPR

Comitê Editorial:

Elisângela Scaff (UFPR)

Daniela de Oliveira Pires (UFPR)

Ana Lorena Bruel (UFPR)

Conselho Editorial: 
SILVA, L. G. A. da. Novos parâmetros de gestão na escola pública: o perfil e os sentidos meritocárticos contidos no processo de reforma educacional na rede pública estadual de ensino de Goiás

Andréa Barbosa Gouveia (UFPR), Ângela Hidalgo (Unicentro), Cesar Gernomino Tello (Universidad Nacional TresFebrero, Argentina), Gladys Beatriz Barreyro (USP), Juca Gil (UFRGS), Jefferson Mainardes (UEPG), João Ferreira de Oliveira (UFG), Luiz Souza Júnior (UFPB), Marcos Edgard Bassi (Ufsc), Regina Maria Michelotto (UFPR), Robert Verhine (UFBA), Rosana Cruz (UFPI), Rubens Barbosa Camargo (USP), Sebastián Donoso Díaz (Universidad de Talca, Chile), Taís Moura Tavares (UFPR), Theresa Adrião (Unicamp), Vera Peroni (UFRGS).

Créditos e Agradecimentos:

Revisão de Língua Portuguesa, Abstract e Resumen: PROGRAMA DE APOIO ÀS PUBLICAÇÕES CIENTÍFICAS PERIÓDICAS DA UFPR

Arte e diagramação: TIAGO TAVARES (tiagotav@gmail.com)

Jornal de Políticas Educacionais

Universidade Federal do Paraná

Setor de Educação

Núcleo de Políticas Educacionais - NuPE/UFPR

Avenida Sete de Setembro, 2645

$2^{\circ}$ andar, Sala 213

80.230-010 - Curitiba - PR - Brasil

Tel.: 41-3535-6264

jpe@ufpr.br

http://revistas.ufpr.br/jpe 